\title{
Empowered Mobility: Supply Chain Thinking for Youth in Foster Care
}

\author{
DEBORAH RICHMOND \\ Woodbury University
}

The application of global container logistics to highmobility children, such as those in foster care, asks designers to consider an empathic, human-centered approach to an institutionalized system of involuntary mobility, which can result in as many as 3-4 family "placements" per year for some children. In spite of grim statistics for youth in foster care related to graduation, teen pregnancy, drug use and imprisonment, these children develop many positive resiliencies around adaptability, emotional intelligence, empathy and efficiency. Working with a non-profit serving youth in foster care in Watts, Los Angeles, called Peace4Kids, whose motto is "community as family," the concept of a "mobile village" was born. Following their lead, paired with a deep understanding of consumer culture's collective intelligence around moving goods through cities, an innovative strategy was used to create a literal delivery platform for educational programming, in partnership with other non-profits, around food equity, social justice and eventually other vocational skills such as apparel arts, machine arts, fine arts and early education.

\section{LOGISTICS, GEOGRAPHY AND COMMUNITY}

Arriving at the Ports of San Pedro in Los Angeles, shipping containers filled with consumer goods fan out through a local network of transportation corridors, marking the city indelibly with deep infrastructure. As a system of mobility, the containerized supply chain is without equal as a model of object-centered design thinking, efficiency and positive outcomes for the corporations it serves.

The application of global container logistics to high mobility children, such as those in foster care, is born of the notion that transportation logistics can also democratize the distribution of human experience and activities, and not only the Cartesian distribution of goods. Exploiting the positive qualities of efficiency and adaptability (intermodality in logistics-speak), allows for the use of the systems thinking embedded within the supply chain as a framework, and delivering a human-centered response to the needs of this highly mobile population, that suffers due to its endemic and involuntary mobility, which disrupts the individual's capacity to dwell in one place, form relationships and benefit from sequential learning environments. Using techniques of classical design thinking, a mobile village was created that borrows the physical attributes and technologies of consumer logistics to provide a consistent distribution of educational and community experiences to children whose caregivers cannot, will not or don't know how, to bring them to the various non-profits and service providers that support foster families.

In fact, nonprofits serving youth in foster care are not the only nonprofits that suffer from the fragmented geography of Los Angeles County. A study commissioned in 2010 by a foundation that specializes in "capacity-building," that is, scaling up internal staff, program offerings and expanding outreach to the communities they serve, it was noted that:

"In order to address geographic gaps in service, capacity-building providers should explore ways that they can extend place-based services to under-served areas of Los Angeles County. Some possibilities include offering a greater number of webinars and establishing joint satellite offices out of which multiple providers could offer services that require in-person meetings, such as trainings and peer exchanges." ${ }^{\prime 1}$ [emphasis added]

The 2013 State of the Nonprofit Sector in Los Angeles Report further noted the existence of "desert neighborhoods," predominately poor and African-American in Los Angeles County, which were lacking any established nonprofit human services organizations. ${ }^{2}$ This is a sadly ironic finding indeed, as these are of course the neighborhoods that need these services most. Clearly, the need to actually distribute services-not goods-throughout Los Angeles County is a pressing one, but bricks and mortar solutions are often cost-prohibitive.

\section{ARCHITECTURE WILL FIX EVERYTHING}

This is where architecture, a field that specializes in solving systemic design problems using a creative and spatial approach, is uniquely poised to take on the problem of essentially moving services that require physical shelter to people who cannot access them and for 


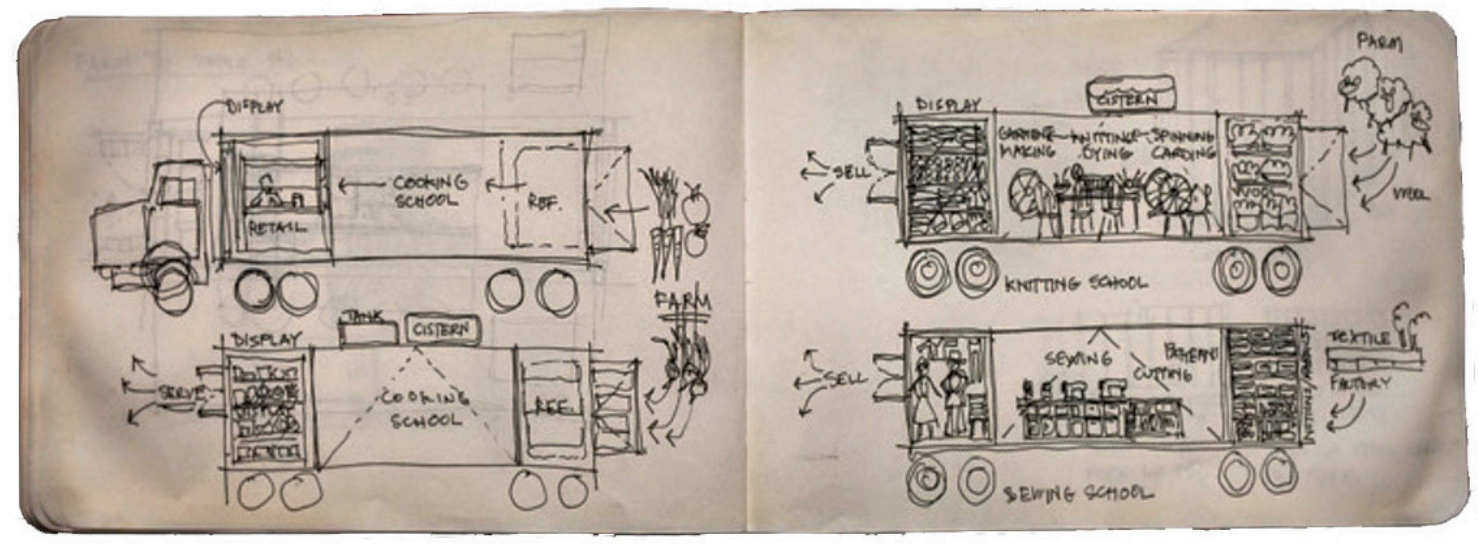

Figure 1: Mobile Village concept sketches by author, c. 2013..

which a digital platform is inadequate as a means of distributing content. When I first published an essay about the Alameda Corridor in Los Angeles in 2004, about consumer goods movement between China and the U.S., it was from the perspective of a critical landscape urbanism, looking at containerization as an organizational system of order (distinct from looking at containers as buildings). ${ }^{3}$ Drawing on theoretical positions of urban form borrowed (stolen), from a certain analysis of urban form in Manhattan, this essay looked at the relationship between human psychology, geography and a piece of hard, urban, infrastructure. It is difficult to imagine a trade besides architectural design that would allow for cross-disciplinary ruminations that produce virtually no actionable data. And yet, making these connections is essential to finding innovative solutions to sheltering human activities amidst a situation of such challenging urban geography. Similar issues were explored in my 2008 essay, "Consumers Gone Wild!" in the book Infrastructural City. ${ }^{4}$ In this essay, the connection was made between warehouse and big-box buildings and the rest of the supply chain. The argument in this case was that the distinction between buildings that store or present objects and the steel boxes that move them is very slim and in fact, a spatial continuity exists between the part of the system that moves and the part that is immobile. It is interesting to note that in French, the word for building, as pertains to its cultural status and not its action state as a constructed object (bâtiment), is immeuble, which means "immobile," as opposed to "meuble," which refers to furniture. Thus, a building is simply the thing that does not move. Usually.

Photography proved to be a useful tool to observe and document these continuities. For example, the loading dock at the neighborhood supermarket yielded every feature of a mobile shipping trailer, including leveling legs, taillights and especially its materiality, which was reflected in the materiality of the building it sat adjacent to. Additional photos of the massive mega-warehousing complexes that distribute goods up and down the west coast in the U.S. along I-5 similarly revealed the "kit-of-parts" relationship between spaces of mobile storage and spaces of immobile storage. As photogenic as the logistical ballet of containerization is, however, the little pieces that live in the interstices of trailers, trucks, ships and buildings are actually the most profoundly fraught with meaning imparted from decades of international negotiations, industrial and mechanical engineering: the fork-lift slots, corner posts and fittings, twist-locks, clamps and connectors constitute a pre-engineered system within which boxes of space are permitted to exist, much like a zoning envelope does for buildings. ${ }^{5}$ These machine parts organize a spatial envelope within which an architect can deploy the traditional design skills around tectonics, form and materiality.

\section{FROM CRITICAL POSTURE TO DESIGN FOR SOCIAL IMPACT}

By 2013, moving beyond the critical observation phase of the "exquisite corpse" of the consumer supply chain, whose main objective contributes to the utter depletion of the planet's raw materials and enables the exploitation of factory workers worldwide, the problem presented itself as to how an architect could actually engage the supply chain within the confines of the architect's standard of care, which includes notions of serving in the public interest and for the public good. Improving the efficiency of the consumer supply chain, besides the fact that we lack the expertise to do so, accomplishes neither of these goals. On the other hand, if there is a real human problem to solve around shipping that falls within the purview of design thinking if not architecture outright, it is the problem of fair trade. Fair trade suffers from the status quo of horizontally integrated, third party shippers because the lack of transparency in the supply chain precludes fair trade certification. ${ }^{6}$ As a system of design, horizontality is problematic because of the deep opacity it breeds in the lateral connection between producers and consumers: it is like trying to look lengthwise through a 1,000 foot long tube of glass:

"The Fairtrade system requires these products to be physically traceable. This means they must be labelled and kept separate at every stage of their journey from the farm to the shop shelves."7

Considered as a spatial design problem then, if horizontality does not work, then what about verticality? What would that look like? What did it look like in the past? As a classic historic example, trucking fleets 


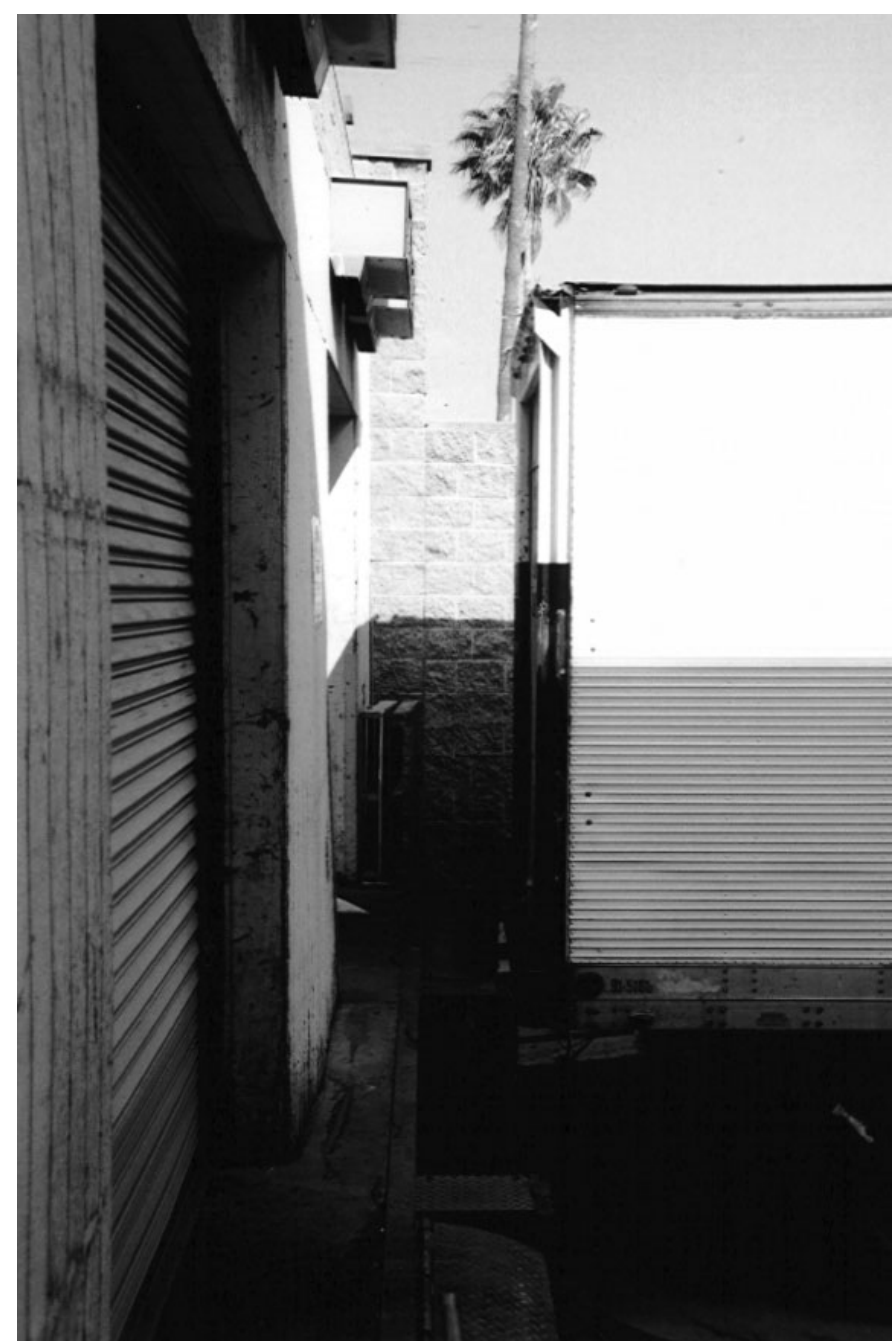

Figure 2: Loading dock, Ralph's Supermarket, photo by author, c. 2001.

were once owned and operated by the grand old department stores themselves before the container was evolved. The retailer's value chain recessed much further up the supply chain than it does today, sometimes including the trucks and warehouses from which goods were procured. In another example, ocean-bound shippers might also own and brand a fleet of trucks on land or rail cars. And today, some retailers work back up to the shipping container itself, but without including the systems of mobility that trucking and shipping companies provide. For fair trade, the creation of a vertically integrated supply chain that still benefits from the logistical continuities of containerized shipping could give fair trade shippers the cost savings they would need to price goods competitively with horizontally integrated shippers, such as Walmart, which use suspect certifications that do not include the supply chain itself, leaving a gap between the regulation of the farming coop at one end and fair trade marketing to the U.S. consumer on the other end. What then, might a "vertically integrated supply chain" look like today?

This avenue of research produced informal studies for a prototype fair trade "supply chain" (see Figure 1), in which a horizontality is collapsed, accordion style, into one shipping unit, which in logistics parlance is "vertical integration." It included components for loading raw materials into one end, an expandable platform for processing artisanal goods in the middle, and a display window and retail post at the other end. In this way, the processes of raw material extraction, manufacturing, warehousing, transport and retail distribution were contained in a single shipping unit-not a retrofitted container, but a custom-designed and fabricated container that nevertheless used the same existing structural transportation and hardware specs that would allow it to travel intermodally between ship, rail, truck and parking lot. As an architectural problem, this was about bringing human activities right into the heart of the supply chain's spatial tectonics and creating a new program beyond goods movement-but still including movement. This is not a project about stripping containers of their mobility and re-purposing them as buildings: it is about investing mobile units with the sheltering of human activities that remain mobile as part of their program.

\section{ON THE GROUND, ON WHEELS}

This distinction has led to two avenues of exploration. On the one hand, the compression of the vertical supply chain for fair trade is still about moving goods-albeit a very specialized subsector of goodsfrom producer to consumer. On the other hand, the re-purposing of the horizontal supply chain to move experience-based activities, not goods, has also grown out of this research.

The first organization to benefit from this exploration was a nonprofit organization called Peace4Kids, serving youth in foster care in Los Angeles. They have nothing, ostensibly, to do with fair trade. But they did have an interesting problem that involved the location and movement of their educational activities and programming. Let me back up and say that my architectural practice had been providing pro bono services for a year at that point, to help them design a learning kitchen. The kitchen was to be located in the Watts Willowbrook Boys and Girls Club, the facility they rented for their Saturday programming. Peace4Kids' Saturday programs are rich educational and bonding experiences for youth in foster care with the tagline "community as family." It is an extremely effective organization that serves a population of kids who may have to live through an average of seven placements in seven different families as a part of their foster care experience. Sometimes, even siblings could only find each other at the Saturday program. The beauty of the programming model is that wherever the kids are "placed," Peace4Kids is an always-on network of peers and caregivers. But there was a problem that highlighted the risks of substantial capital investment-bricks and mortar-for growing nonprofits: the Boys and Girls club was undergoing a leadership change and there was concern that Peace4Kids' lease might not be extended. The thought of investing a large chunk of cash into renovating a space in the building for the learning kitchen just did not make sense. Sadly, at that moment, the stable community for these high-mobility kids was experiencing it's own foster care moment and might have needed to move. At that point, putting the program on wheels seemed like a manageable commitment of capital resources and one that could potentially transform the nature of the organization. 


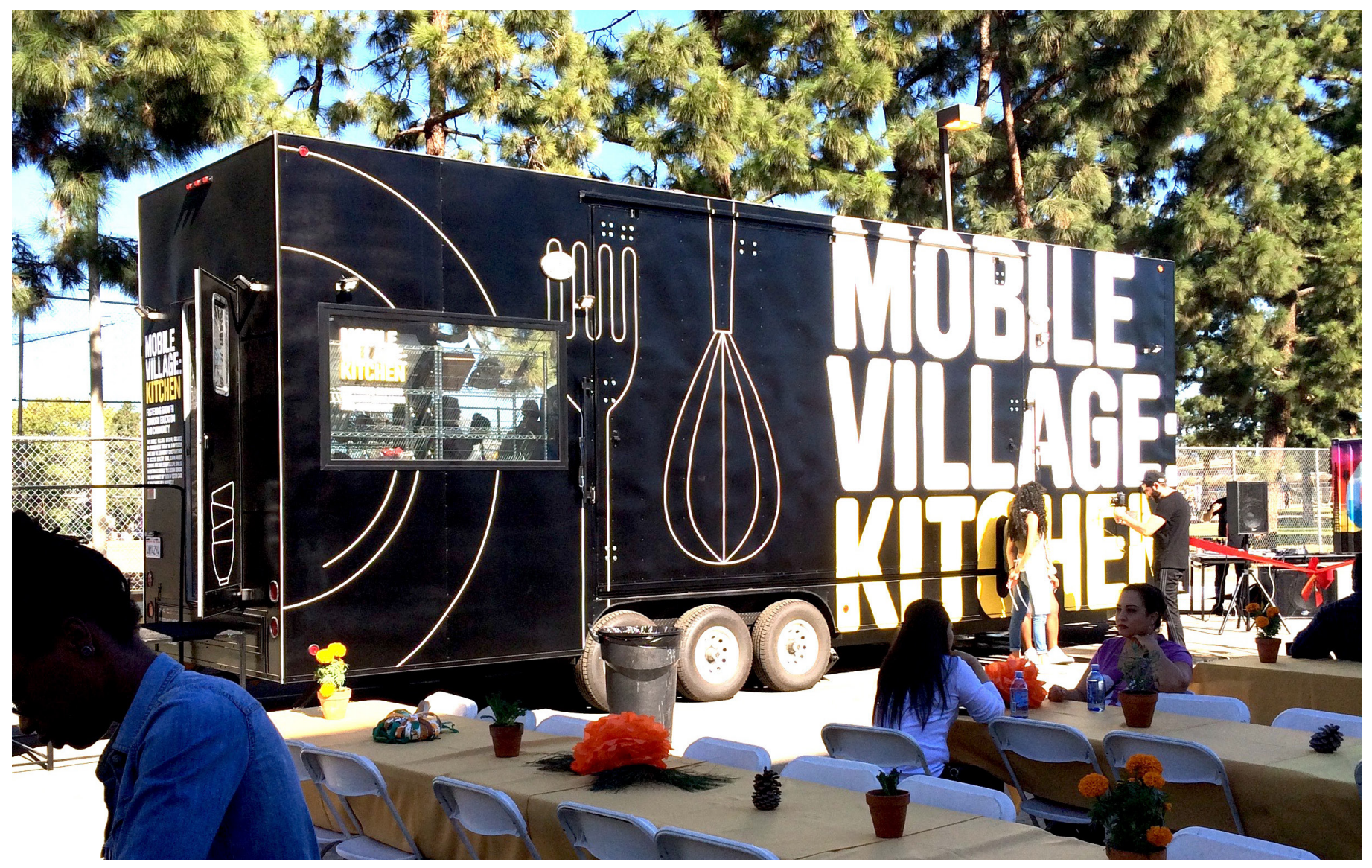

Figure 3: The Mobile Village: Kitchen opening day, November, photo courtesy Hannah Childe, c. 2015.

Through a series of workshops with the youth in the program, the mobile trailer was imbued with a deeper meaning and created a mission and guiding path for the movable experience. The mobile, adaptable trailer was a metaphor for their own experiences, in which the whole notion of family, community and culture was already perpetually mobile experience. What the initial sketches for fair trade provided was a design focus and template for the trailer itself as a shelter for human-centered activities, such that rather than swallow container logistics whole and try to cram a kitchen into a shipping container, we embarked upon a solution that allowed for the strategic re-design of the container itself from scratch, while conforming to the transportation logistics it would need to interact with to remain mobile. In truth, once a shipping container stops moving, it's just a dumb, over-structured steel box of space. It's the intermodailty of the box that makes it interesting, the fact that it can keep moving.

Because of course, in a city like Los Angeles, with a territory of over 1,700 square kilometers, foster kids are also, always on wheels. Besides the expediency of owning a mobile asset not connected to real property, the program now seeks to keep up with the kids themselves, relying on Los Angeles's superb granularity of highway infrastructure as a strength for connecting people, not only things. In addition to performing as a mobile cooking school, in true supply chain fashion, the trailer can also pick up the "raw materials" of locally grown, organic food, from Los Angeles's many urban farms. This has helped the organization to form new partnerships with other nonprofits whose missions align with theirs

Ultimately, we learned from the youth in the program that the mobility that they were forced to experience actually empowered them with some pretty fantastic qualities: adaptability, flexibility, a minimalist outlook regarding possessions and other resiliencies that could be celebrated as remarkable and common characteristics that this population could take pride in. In the face of dire and depressing statistics about graduation rates, imprisonment, drug addiction and even death, here was a new identity emerging that together, as a community, these children and teens could claim ownership of. The Mobile Village: Kitchen came to symbolize this positive, adaptable and innovative identity. Working with graphic designers at $2 \times 4$ in New York, the identity and branding was further refined to create a compelling image of adaptable simplicity.

\section{SCALING UP}

The Mobile Village is on its way to becoming a social enterprise startup. It is to experience-based programming what containerization is to consumer goods: a third-party delivery platform extending the reach and penetration of the organizational entity that deploys it. While the initial study about fair trade focused on scenarios involving vertically integrated activities, the Mobile Village has in one sense gone full circle, to provide the efficiencies of horizontal integration to a broad range of activities. The first prototype trailer was completed 


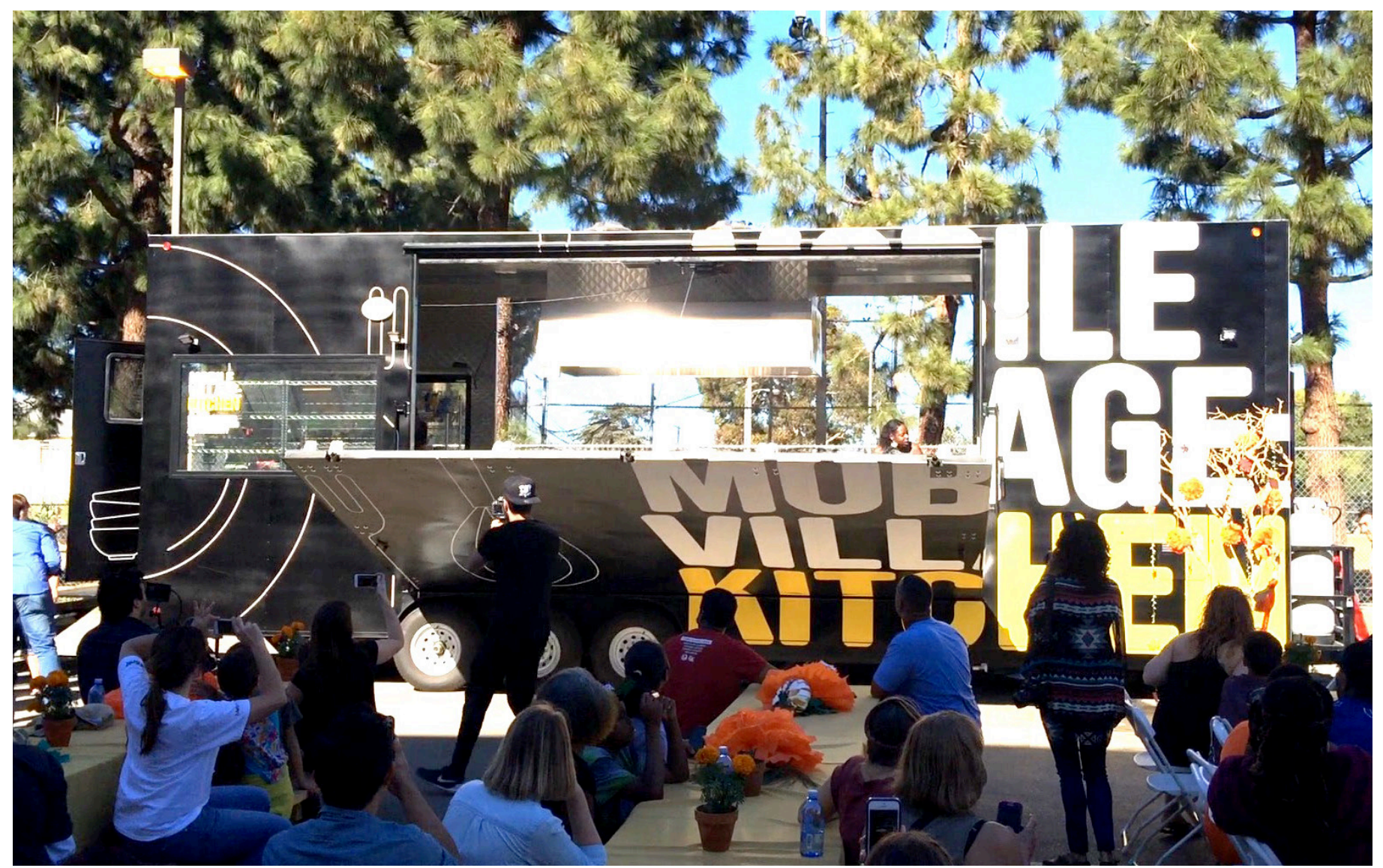

Figure 4: Mobile Village: Kitchen in Watts, Los Angeles, film still, courtesy Mira Zimet, c. 2015.

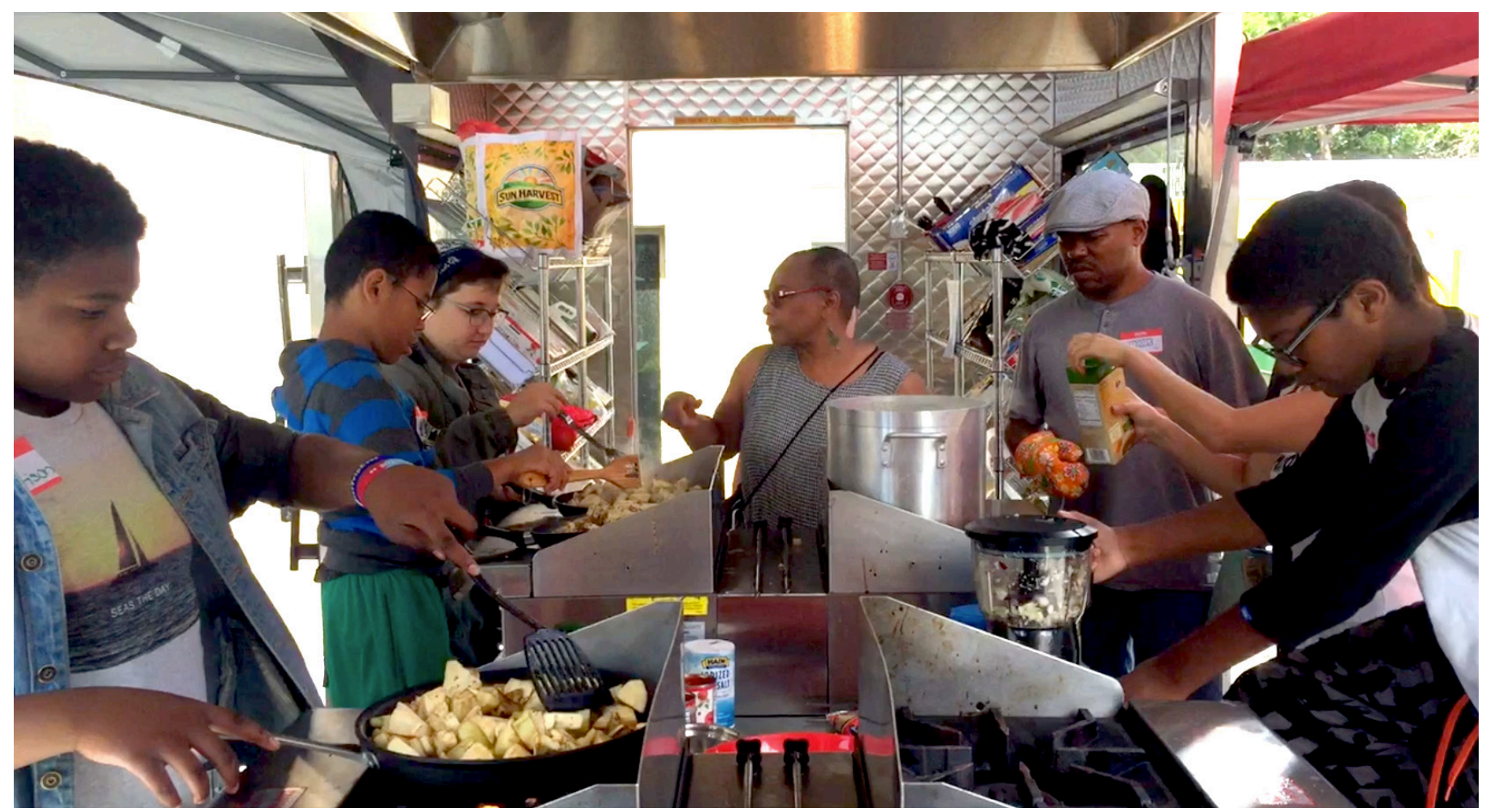

Figure 5: Mobile Village: Kitchen, interior, film still by Alan Manning, c. 2016. 
last fall, and already we are tracking feedback-testing-if you will, in order to build the next one. In order to move the trailer, we have contracted with a trucking company that provides the nonprofit with bulk rates to pick up, transport and deliver the kitchen to different sites. The kitchen is currently staffed by another nonprofit, called Kitchen Divas, who create and administer cooking curriculum for Peace4Kids. Peace4Kids has also partnered so far with three other organizations: L.A. Kitchen, a nonprofit providing vocational education for cooking careers in downtown L.A.; the Food Policy Council, and amazing organization that seeks to change public policies that create barriers to healthy eating in our food deserts; and the L.A. Food Festival, an event that celebrates the diversity of Los Angeles's food culture So far, although the dream of showing up every Saturday at a new location in the county and providing a cooking class has not yet materialized, Peace4Kids is seeking a partnership with the Los Angeles County Department of Parks and Recreation for a consistent infrastructure of public spaces in which to operate. In a poignant "cycle of life moment," Peace4Kids first full-time cooking instructor will be a program alum who has just completed L.A. Kitchen's vocational training and received his safe food handling certification from the State of California.

The Mobile Village as a separate entity, will continue to contract with other nonprofits, to lease vehicles for use as moving buildings for experiences-based programming. As we move forward, the original design continues to be refined and expanded to include other non-cooking spaces for art classes, music education and sound engineering, a literacy library, and ultimately mobile housing for organizations serving the homeless. In doing so, The Mobile Village fleet will fulfill its mission to be a capacity building device for the growth and expansion of any human services nonprofit.

\section{ENDNOTES}

1. Fortifying L.A.'S Nonprofit Organizations: Capacity-Building Needs And Services In Los Angeles County, A Study by TCC Group Commissioned by the Weingart Foundation, September 2010.

2. Spread Thin: Human Services Organizations in Poor Neighborhoods, Ralph M. Parsons Foundation sponsored report by UCLA Luskin School of Public Affairs, 2013.

3. Richmond, Deborah. "Divestitures," in Log 3, ed. Cynthia Davidson, Fall, 2004.

4. Richmond, Deborah. "Consumers Gone Wild," in Infrastructural City: Networked Ecologies in Los Angeles, ed. Kazy Varnelis, Actar, c. 2008.

5. Levinson, Marc, The Box, Princeton University Press, Princeton, c. 2006, p. 56.

6. Ward, Kevin. Drop Shipping, an Uneven Playing Field, Fair Trade Federation, http:// www.fairtradefederation.org/wp-content/uploads/2013/01/Drop-ShippingAdvice-for-Wholesalers.pdf, accessed on 07/25/16.

7. Haight, Colleen. The Problem with Fair Trade Coffee, The Stanford Social Innovation Review, http://ssir.org/articles/entry/the_problem_with_fair_trade_coffee, accessed on $07 / 25 / 16$.
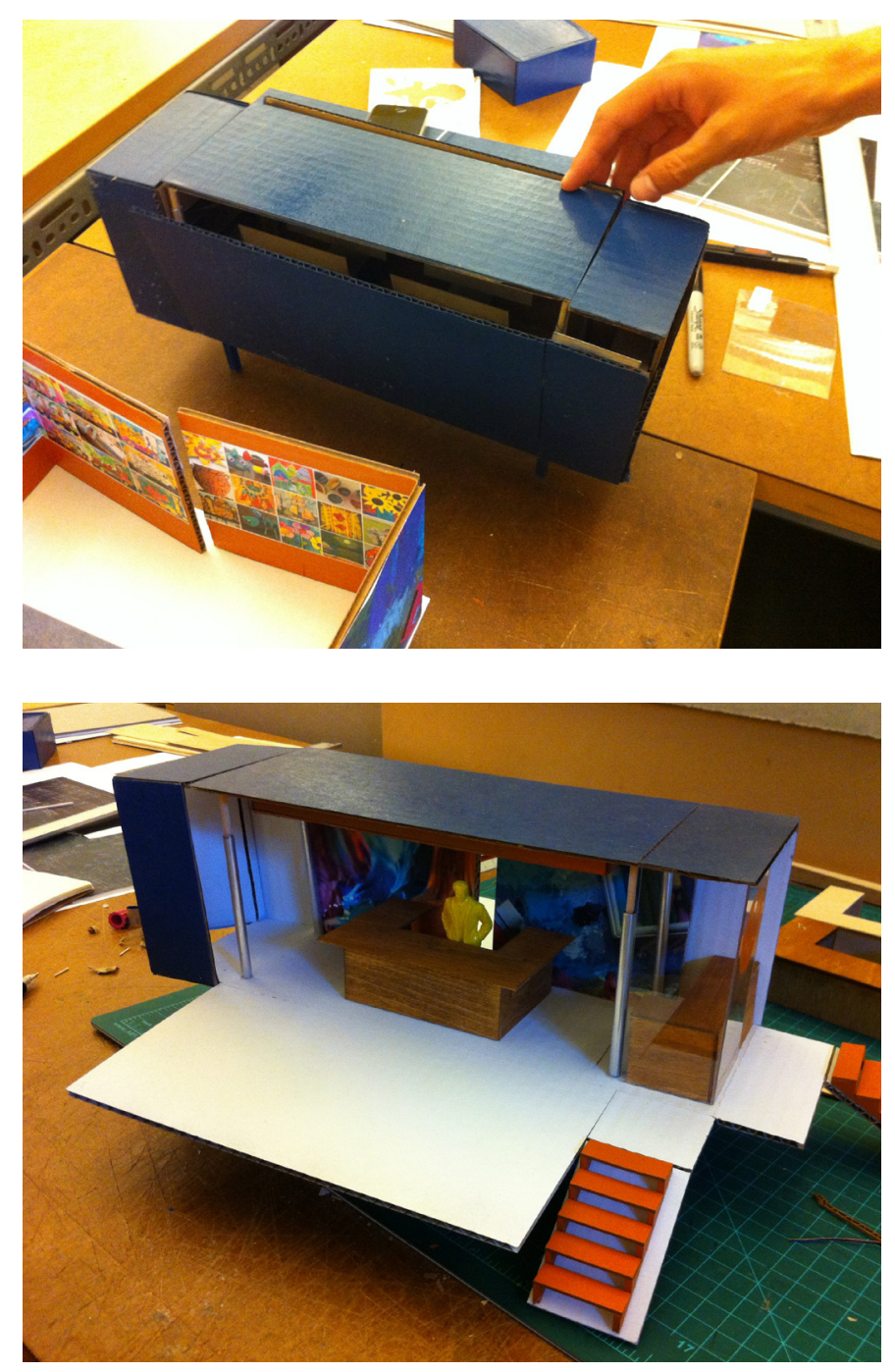

\section{PROJECT CREDITS:}

Architectural and product design: Deborah Richmond, Vedi Vartani, Alan Manning

Graphic design: 2 × 4 NY

Community input: Peace4Kids staff and program participants.

Funding partners: JIB Foundation, Small Business Administration, Laila Ali 